\title{
MODOS DE CUIDAR EM COMUNIDADES RURAIS: A CULTURA PERMEANDO O CUIDADO DE ENFERMAGEM ${ }^{1}$ WAYS OF CARE IN RURAL COMMUNITIES: CULTURE PERMEATING THE NURSING CARE MODOS DE CUIDAR EN COMUNIDADES RURALES: LA CULTURA ORIENTANDO EL CUIDADO DE ENFERMERÍA
}

\author{
Maria de Lourdes Denardin Budó2, Rosita Saupe ${ }^{3}$
}

\begin{abstract}
${ }^{1}$ Trabalho com base na tese de doutorado: "A prática de cuidados em comunidades rurais e o preparo da enfermeira" (Denardin Budó, 2000), defendida no Programa de Pós-Graduação em Enfermagem da UFSC.

${ }^{2}$ Enfermeira. Professora adjunto Departamento de Enfermagem - UFSM. Mestre em Extensão Rural pela UFSM e Doutora em Filosofia da Enfermagem pela PEN/UFSC. Membro do Grupo de Pesquisa Cuidado, Saúde e Enfermagem.

${ }^{3}$ Enfermeira. Professora do Curso de Mestrado Profissionalizante em Saúde da Família - UNIVALI. Doutora em Enfermagem - USP.
\end{abstract}

PALAVRAS-CHAVE: Cultu- RESUMO: Trata-se de pesquisa qualitativa com objetivo de identificar as práticas de cuidado de ra. Enfermagem em saúde co- enfermeiras que trabalham nas Unidades Básicas de Saúde de municípios rurais do Rio Grande do Sul munitária. População rural. e identificar o preparo recebido, para o cuidado dessa população. Foram utilizadas, para a coleta de dados, a análise documental, a observação participante e a entrevista, sendo os mesmos analisados em seu conteúdo. Estes dados referem-se à descrição do modo de cuidar das nove enfermeiras que trabalhavam com a população destas comunidades. Para fundamentar o estudo foram trabalhados três conceitos centrais, Comunidade Rural, Cuidado de Enfermagem e Preparo da Enfermeira. Constatou-se que as enfermeiras são referência para a população, desempenhando diferentes papéis, tanto na equipe de enfermagem, como na relação com outros setores da comunidade. O trabalho também reflete a influência da cultura do meio rural e as estratégias utilizadas pelas enfermeiras para o seu preparo visando um cuidado adequado.

KEYWORDS: Culture. Community health nursing. Rural population.
ABSTRACT: A qualitative research was developed with objective to identify the care practices of nurses who work in the Basic Units of Health of rural cities of the state of Rio Grande do Sul and to identify the preparation received to care for this population. Documentary analysis, participant observation, and interviews were used for the data collection, analyzing them within their content. This data refers to the description of the ways of caring by nine nurses who worked with the population of these communities. In founding this study three central concepts were used: Rural Community, Nursing Care and Nurse Preparation. We evidenced that the nurses are a reference for the population, playing different roles in both the nursing team and their relationships with other sectors of the community. The work also reflects the influence of culture of the rural environment and the strategies used by the nurses for their preparation aiming an adequate care.

PALABRAS CLAVE: Cultu- RESUMEN: Se trata de investigación cualitativa con objetivo de identificar las prácticas del cuidado ra. Enfermería en salud de enfermeras que trabajan en las Unidades Básicas de Salud de municipios rurales de Río Grande del comunitaria. Población rural.
Sur e identificar la preparación recibida, para el cuidado de esa población. Fueron utilizados, para la recolección de datos, el análisis de documentos, la observación participante y la entrevista, siendo los mismos analizados en su contenido. Estos datos se refieren a la descripción del modo de cuidar de las nueve enfermeras que trabajaron con la población de estas comunidades. Para fundamentar el estudio fueron utilizados tres conceptos centrales: Comunidad Rural, Cuidado de Enfermería y Preparación de la Enfermera. Se constató que las enfermeras son referencias para la población, desempeñando distintos papeles, tanto en el equipo de enfermería, como en la relación con otros sectores de la comunidad. El trabajo también refleja la influencia de la cultura del medio rural y las estrategias utilizadas por las enfermeras para su preparación con miras a un cuidado adecuado.
Endereço:

Maria de Lourdes Denardin Budó

R. Appel, 800 Apto 208

97015-030 - Santa Maria, RS

E-mail: lourdesd@viars.com.br
Artigo original: Pesquisa

Recebido em: 10 de outubro de 2004

Aprovação final: 8 de março de 2005

Texto Contexto Enferm 2005 Abr-Jun; 14(2):177-85. 


\section{INTRODUÇÃO}

Evidenciar os modos de cuidar em enfermagem, suas múltiplas facetas, seu registro e divulgação torna-se elemento fundamental para a sua problematização e busca de novos caminhos na prática desta profissão. Um dos grandes desafios da enfermagem na atualidade constitui-se em aliar a sua prática com a das pessoas cuidadas, buscando na alteridade, alternativas de cuidado mais coerentes com as suas necessidades. Alteridade aqui entendida como a capacidade de conviver com o outro, que é diferente, e reconhecê-lo como sujeito de direitos iguais, na busca da cidadania. Nesta vertente, a perspectiva cultural do cuidado se insere como elemento que poderá contribuir para práticas mais adequadas e aproximadas às pessoas. A abordagem de cultura partilhada neste trabalho tem por base a concepção ${ }^{1}$ que a define como um conjunto de teias e significados que o próprio homem teceu e na qual se encontra amarrado. Neste sentido, a cultura constitui-se no vivido cotidianamente, significando ação humana, simbolismo. Para o autor, "olhar as dimensões simbólicas da ação social [...] é mergulhar no meio delas" $1: 40$.

Para compreender a prática da enfermagem torna-se necessário olhar, guiado por um método, o que seus atores fazem no seu dia a dia e, neste sentido, sabe-se de antemão que o olhar do pesquisador é impregnado de seu próprio simbolismo e do significado que sua cultura pessoal e profissional o impregnou. Neste artigo busca-se articular cuidado em enfermagem e cultura, através da apresentação de parte dos resultados de uma pesquisa realizada em comunidades rurais do Rio Grande do Sul, que contempla o trabalho desenvolvido pelas enfermeiras nas Unidades Básicas de Saúde, nestas localidades. Os objetivos do estudo ${ }^{2}$ foram identificar as práticas de cuidado desenvolvidas pelas enfermeiras que trabalham com a população dos municípios da $4^{\mathrm{a}}$ Colônia de Imigração Italiana do Rio Grande do Sul e identificar o preparo recebido pelas mesmas, para o cuidado da população rural.

\section{METODOLOGIA}

A proposta metodológica para este trabalho constitui-se numa abordagem qualitativa da realidade, através de caminhos e instrumentais próprios. Para trabalhar o problema proposto, tornou-se fundamental conhecer a realidade da prática do cuidado desenvolvido pelas enfermeiras do local de estudos, as interfe- rências das políticas de saúde para o setor, bem como a percepção das enfermeiras em relação à sua formação em nível de graduação, pós-graduação e educação continuada. Todos estes elementos forneceram dados para obtenção de um panorama abrangente do trabalho desenvolvido por estas profissionais e dos modelos de cuidado oferecidos à população.

Os sujeitos que fizeram parte da pesquisa foram as nove enfermeiras que atuavam na rede pública dos municípios que constituem a Quarta Colônia de Imigração Italiana: Dona Francisca, Faxinal do Soturno, Ivorá, Nova Palma, Pinhal Grande, São João do Polêsine e Silveira Martins, no período de março a agosto de 1999. Considerando-se a proposta de pesquisa, seus objetivos e questões, optou-se por utilizarse a análise documental, a observação participante e a entrevista, técnicas importantes para fornecer os dados necessários para análise. A entrevista constituiu-se de questões abertas e fechadas, visando conhecer o pensamento das enfermeiras sobre o seu trabalho e a sua formação acadêmica. Foi gravada e transcrita literalmente após a sua realização. Os documentos analisados foram os Planos Municipais de Saúde e os Regimentos dos serviços de enfermagem de cada município estudado. Foram integrados estes três métodos de coleta, visando a convergência dos dados, através da triangulação de método, o que representa uma possibilidade de maior credibilidade da pesquisa qualitativa, proporcionando "uma base de convergência da verdade" ${ }^{\text {3: } 211 .}$

$\mathrm{Na}$ busca de interpretar os elementos encontrados nas diferentes formas de captação dos dados, foi utilizada a análise de conteúdo, que evidencia os significados manifestos e latentes. Esta análise foi constituída de três fases ${ }^{4}$, conforme análise temática: a préanálise, a exploração do material e o tratamento dos resultados obtidos e interpretação.

Em todas as etapas deste trabalho houve a preocupação com as questões éticas, levando em consideração a Resolução no 196/96 volvendo seres humanos. Para tanto, buscou-se o consentimento livre e esclarecido dos sujeitos da pesquisa, através da apresentação do projeto e assinatura de autorização para que fosse realizada a observação do trabalho e a entrevista com a enfermeira.

\section{RESULTADOS}

A abrangência do estudo foi delimitada aos sete municípios que constituem a Quarta Colônia de Imigração Italiana. Estes municípios, originalmente per- 
tencentes à Colônia de Silveira Martins, são histórica, geográfica, social, cultural e economicamente tidos como rurais. Sua população, direta ou indiretamente, sobrevive dos produtos originários da terra e tem as características sociológicas e culturais atribuídas às comunidades rurais: a relação direta com a natureza e a relação estreita entre os seus membros. Estes municípios, além de possuírem características sociológicas rurais, têm um comportamento assemelhado ao rural, embora juridicamente sejam considerados urbanos ${ }^{6}$. Além desta caracterização, esta população apresenta outro elemento de fundamental importância: o caráter familiar da produção, não só na maneira como é organizado o processo de trabalho, mas nos processos de transferência hereditária e sucessão profissional.

Através de movimentos locais, os antigos núcleos de imigrantes iniciaram processos de emancipação, que se deram a partir de 1959, com a criação do município de Faxinal do Soturno; 1960, Nova Palma; 1965, Dona Francisca; 1987, Silveira Martins; 1988, Ivorá; 1992, São João do Polêsine e Pinhal Grande. Nos últimos anos há um crescente movimento na perspectiva do desenvolvimento desta região. Alguns moradores, administrações municipais e estadual, bem como setores das universidades locais, dentre elas a Universidade Federal de Santa Maria (UFSM), preocupados em criar alternativas de crescimento das potencialidades locais, têm se voltado para a elaboração de projetos que visam ao resgate do patrimônio histórico-cultural da antiga colônia, bem como a busca de alternativas que viabilizem a melhoria das condições de vida e de trabalho dos moradores destes municípios.

Percebe-se, com isso, uma retomada da valorização do imigrante e seu patrimônio cultural, em atividades das escolas municipais, nas reuniões comunitárias e nas programações das administrações municipais, através do ecoturismo e de programações culturais na agenda de cada município da Quarta Colônia. Cada um deles tem seus próprios encantos, pela exuberância da natureza e pela possibilidade do resgate do patrimônio histórico-cultural, que tem proporcionado a valorização das atividades étnico-culturais da região.

$\mathrm{Na}$ época da coleta dos dados o Sistema de Saúde dos Municípios da Quarta Colônia estava organizado através do Conselho Municipal de Saúde, Fundo Municipal de Saúde, Secretaria Municipal de Saúde e Bem Estar Social. Cada Município possui um hospital na sede, variando entre vinte e dois e quarenta e sete leitos, sendo que a maioria destes são destinados ao Sistema Único de Saúde (SUS). A rede pública era constituída, geralmente, por uma Unidade Básica de Saúde na sede do município e outra na comunidade rural maior. Os recursos de apoio e diagnóstico públicos e privados, conveniados, eram os laboratórios vinculados ao hospital local, Hospital Universitário da Universidade Federal de Santa Maria (HUSM) e serviços prestados através do Consórcio Intermunicipal de Saúde (CIS). Através do CIS, a rede era ampliada para o encaminhamento às diferentes especialidades na região e Estado.

\section{Caracterização das enfermeiras}

As enfermeiras que trabalhavam na rede ambulatorial destes municípios estavam vinculadas às respectivas Prefeituras, desempenhando algum papel relacionado com a Secretaria de Saúde e Bem Estar Social sendo, em alguns casos, a titular desta secretaria.

Quanto ao número de enfermeiras, cada um dos municípios estudados possuía uma ou duas enfermeiras trabalhando na rede pública de saúde. O contrato de trabalho era como estatutárias, através de concurso público ou como cargo em comissão, quando era cargo de confiança. Dos sete municípios estudados, em três a Secretária de Saúde era enfermeira, sendo que em dois municípios, a única enfermeira de Saúde Pública era também Secretária de Saúde do Município. No outro município, a Secretária de Saúde era enfermeira, mas havia outra que assumia o trabalho na Unidade Básica de Saúde (UBS). Em um dos municípios, a enfermeira que assumia a UBS era também a única enfermeira do hospital da localidade. Em outro, na ocasião da coleta de dados, uma das enfermeiras, embora não fosse a Secretária de Saúde, assumiu algumas atribuições desta secretaria, porque a titular estava em licença saúde.

Nos municípios de Dona Francisca, Ivorá e Pinhal Grande estava implantado o Programa de Agentes Comunitários de Saúde (PACS), cuja coordenação era feita por uma enfermeira, com 20 horas de dedicação para este trabalho. Em Pinhal Grande, a única enfermeira foi contratada especialmente para criar o referido programa. Em nenhum dos municípios, na ocasião, havia sido implantado ainda o Programa de Saúde da Família (PSF), por falta de infra-estrutura e verba para isso.

Em relação à procedência das nove enfermeiras que participaram deste estudo, seis eram nascidas na região. Uma das que não nasceram na região, morava há mais de vinte anos na localidade. Quando perguntado se o fato de ser ou não daquela região facilitava o trabalho com as pessoas, as oriundas daquele 
lugar foram unânimes em afirmar que havia uma maior aceitação e um trabalho mais próximo com as pessoas, como refere a fala: com certeza, pois tu falas de uma maneira diferente, tu consegues te comunicar, pois já vives ali, sabes conduzir a conversa. É diferente de alguém que não conhece e tu repassas as informacões. Então, tem coisas que não é preciso perguntar, tu só observas ou, do jeito que a pessoa está falando, tu já sabes direcionar uma orientação. Isto facilita muito sim (e2).

Uma das enfermeiras, que não procedia daquela região, disse que não teve muita dificuldade de se adaptar aos novos costumes e tradições da localidade. Mas sentiu necessidade de conhecer os hábitos e os valores culturais para poder trabalhar adequadamente com eles, até para poder ser entendida, como demonstra a fala: até que não, pelo contrário, eu me sinto muito bem, sou de origem alemã, em outra cidade eu convivia com pessoas de origem alemã e italiana [...] eu tinha dificuldade até para entender os próprios alemães, bem como os italianos. E fui me acostumando, e não sinto dificuldade, agora, em relação à região de italianos daqui. Os costumes são um pouco diferentes, a gente até tem que ser um pouquinho mais dura para colocar as coisas que a gente vê. Certas origens (étnicas) a gente coloca (as orientações) mais suaves e afasta as pessoas, e aqui a gente tem que colocar até meio firme, às vezes. Tu queres que a tua palavra passe, tu tens que colocar com uma postura bem firmezinha, senão não vai (e7).

Percebe-se nestas falas a importância da perspectiva cultural e as diferenças sentidas pelas profissionais ao trabalhar o cuidado em saúde.

Entre as enfermeiras das localidades estudadas, a faixa de idade variava entre vinte e quatro e cinqüenta e um anos. Em relação ao tempo de serviço, a que tinha tem menos tempo de trabalho atuava há dois anos e a contratada por mais tempo já completara vinte e seis anos. Das nove enfermeiras, três tiveram sua graduação na UFSM e seis na Faculdade de Enfermagem Nossa Senhora Medianeira, atualmente Centro Universitário Franciscano. No que se refere à pós-graduação, cinco fizeram especialização, uma estava cursando e três não haviam freqüentado nenhuma especialização. Dentre as que cursaram ou cursavam especialização, três freqüentavam programas em saúde pública ou saúde coletiva, duas em administração hospitalar, uma em enfermagem obstétrica e obstetrícia social e enfermagem do trabalho.

\section{O contexto rural e o modo de cuidar das en- fermeiras}

O trabalho realizado pelas enfermeiras, nestas localidades, sofre a influência do ambiente rural, pois, embora o local de trabalho mais constante da enfer- meira, a UBS, seja localizada na sede do município, tudo o que ali acontece, representa a comunidade rural. No geral, todas as pessoas se conhecem, tanto profissionais como clientes. Parece haver uma maior aproximação entre as pessoas.

No geral, a UBS é central e de fácil acesso à população que reside na sede ou que vem à cidade. Mas, para as pessoas que moram nos distritos, principalmente aquelas que não possuem nenhum tipo de transporte próprio, a distância passa a ser um problema. Muitas pessoas precisam caminhar longas distâncias, levantando muito cedo, para chegar no horário para as consultas e tratamento, como é o caso de uma mulher, que disse ter caminhado durante duas horas para chegar até o posto, às sete horas da manhã. Em algumas localidades, há a possibilidade da utilização do transporte escolar, que diariamente busca as crianças e adolescentes que residem nos distritos, para assistir às aulas na sede do município. Na atualidade, com a municipalização da saúde, praticamente toda a população procura o serviço público para tratamento de problemas de saúde. Em algumas localidades, a abrangência do serviço era de mais de noventa por cento da população, como fala uma das enfermeiras: boje, noventa e cinco por cento da população é atendida pelo SUS. As pessoas descobriram que têm direito e buscam o serviço (e6). Segundo ela, no passado só as pessoas que não tinham recursos econômicos buscavam o serviço público para assistência. Percebe-se, nestas comunidades, uma maior mobilização, neste momento histórico. A comunidade é envolvida, participativa, reivindicadora, negociadora, às vezes, chegando a ser exigente daquilo que aprendeu ser seu direito. Este posicionamento deve-se, essencialmente, às garantias constitucionais e aos novos meios de participação popular, como os conselhos. São conquistas que mudaram não só o acesso como a possibilidade de participar e reivindicar aquilo que é considerado seu direito, especialmente porque são comunidades rurais e as pessoas estão mais próximas.

Nesta inserção ao sistema de saúde está a enfermeira, que é solicitada para intermediar, pois ela é a referência para as pessoas, tendo que saber fazer integração e articular-se com as forças da comunidade para poder efetivar o seu trabalho. Muitas vezes este papel passa a ser o de interceder pelas pessoas para que tenham a assistência necessária.

Como as relações entre as pessoas tornam-se muito próximas no ambiente rural, todos se conhecem. A enfermeira passa a ser uma pessoa de referência importante, especialmente quando ela acumula a secretaria 
de saúde, como é o fato relatado por uma delas: é a típica cidade pequena, todo mundo conbece todo mundo, eles não têm aquele limite, a gente encontra na rua e vão chegando com receita, tu estás no supermercado, por mais que tu fales, olha isso é um assunto para ser tratado lá na secretaria [...](e9)

A prefeitura torna-se o centro de referência para as pessoas que buscam recursos em diferentes setores. Esta dependência dos serviços da prefeitura e de seus profissionais se dá em todas as áreas, mas especialmente naquelas relacionadas ao social, como a saúde, a educação, a moradia e a agricultura, como refere outra enfermeira: especialmente em município pequeno, aprefeitura passa a ser uma referência para qualquerproblema, qualquer situação, qualquer ajuda que puder dar em várias situacoôes, não é só na saúde. Até na própria educação, praticamente dá tudo hoje, para o aluno, oferece tudo. Hoje, não vai para a escola... (quem não quer...) Tem material, tem transporte, tem merenda, tem tudo, tem até a própria assistência social que oferece agasalhos. Não é paternalismo, acho que a educação tem que oferecer mesmo as condicões e as pessoas se acostumam mal e exigem também nas outras áreas (e4).

O desgaste do trabalho da enfermeira, nestes casos, é acumulado com as atividades exigidas pela Secretaria de Saúde e Bem Estar, na qual a titular desempenha diferentes papéis no município e interior para garantir a assistência em saúde e bem estar social. Outra enfermeira resume esta diversidade de atividades na seguinte fala: é assim, eu te diria assim, para resumir, que num município pequeno, [...] tu te desgastas porque se tiver que ir lá no meio do mato, no interior, para ver uma fonte, eu tenho que $i r$, se tem uma reunião em Porto Alegre, eu tenho que ir, se tem qualquer probleminha no posto de saúde para resolver, a secretária tem que ir, eu não tenho assistente social, então qualquer problema social é a secretária que tem que resolver. Fazer uma visita domiciliarpara um paciente que está caindo a casa, a secretária tem que ir, então, por isso que é um corre-corre, tu te desgastas muito por causa disso. Tu tens uma equipe, uma boa equipe que te assessora, tu delegas, atépara sentar eplanejar melhor, mas tu tens que fazer dentro dos recursos que tu tens, não podes fugir. Então, é bastante amplo o trabalho do secretário do interior, acho que mais do que o de uma grande cidade (e9).

As enfermeiras também são procuradas em situações em que os clientes sentem necessidade de que seus problemas sejam resolvidos, quando não encontram outras formas para encaminhar as suas dificuldades, como a situação contida nesta fala: é, tu estás fazendo muitas coisas e não consegues parar para te organizar no teu serviço. A maioria que não consegue marcar consultas vêm para mim e pede para ver se eu consigo. Eu me envolvo demais[...] tenho que encaminhar, referenciar para o HUSM, porque tem muitos que já faz tempo que vêm aqui e não resolvem Texto Contexto Enferm 2005 Abr-Jun; 14(2):177-85. e têm vergonha de falar para o médico, não têm coragem... (e7).

Sente-se, nesta fala, que existe um espaço no trabalho da enfermeira que é ocupado para encaminhar aquelas coisas que ninguém resolve para os clientes. Muitas situações, decorrentes de problemas relacionados ao sistema de saúde, são fontes de angústias para as pessoas. Estas situações podem ser referentes à descontinuidade no diagnóstico e tratamento de doenças, aos problemas em relação à referência e contrareferência, no sistema de saúde, a falta dos medicamentos, entre tantos outros. Estas circunstâncias têm sido referidas por grande parte das enfermeiras como fonte de sofrimento para os clientes e que, de alguma forma, levam também ao sofrimento da enfermeira, quando não consegue dar o encaminhamento necessário.

As atividades desenvolvidas com as pessoas, nas comunidades rurais, são mais difíceis, pois dependem da disponibilidade de tempo das mulheres e homens que estão envolvidos no trabalho agrícola. Os grupos tornam-se praticamente inviáveis, pois, de forma diferente das mulheres que moram na cidade, aquelas que vivem no meio rural, além do trabalho doméstico, participam ativamente na lavoura, o que impede a sua integração nos grupos. Nestes casos, a educação em saúde é realizada mais efetivamente com os escolares, como é a situação referida pela enfermeira: as atividades de grupo são mais dificeis de organizar, porque tudo esbarra no tempo disponivel para elas poderem participar. As mulheres do meio rural estão muito envolvidas com os trabalhos não só do lar, como daquele que fazem com o marido, e como! É uma dificuldade de formar grupos. Então é esta dificuldade que eu tenho, não é que não tenha vontade. E o meu trabalho é com os colégios na zona rural, porque as crianças já estão ali, já fica mais fácil repassar uma informação, mas formar grupos, palestras e reuniões é difícil, a gente já tentou (e2).

A realização das ações da enfermeira, nestas comunidades rurais, compreende também o estabelecimento da relação entre o adoecer e morrer com o estilo de vida, o tipo de trabalho, influenciados diretamente por fatores culturais e a busca de alternativas adequadas para a melhoria da qualidade de vida dos agricultores, muito bem representada pelo que fala a enfermeira: sempre me chamou a atenção a maior incidência de problemas cardiovasculares. Daí a gente começa a trabalhar estas questões, por que a maior incidência de óbitos é por este problema? Por que a morbidade é maior neste e naquele problema? Dai tu começas a analisar várias coisas, desde o estilo de vida, a alimentação, o tipo de trabalho, com o que eles trabalham. Dai tu comeģas a trabalhar estas questões. Mas isso é muito lento, porque vai passar por uma mudança de mentalidade (e9).

Fica evidente, nesta fala, a presença de elemen- 
tos culturais que interferem diretamente na vida do agricultor e da família rural, representada pelos hábitos alimentares e pela relação estabelecida no trabalho, que se refletem na qualidade de vida e na saúde das pessoas. Esta percepção do aspecto cultural se fundamenta no fato de que a formação cultural influencia muitos aspectos da vida das pessoas, interferindo fortemente na saúde e seu cuidado. Esta influência se refere às crenças, comportamentos, percepções, emoções, linguagem, religião, alimentação, imagem corporal, atitudes frente à doença, à dor e outros desequilíbrios ${ }^{7}$. Desta forma, o agir profissional, a despeito de quais sejam suas prioridades, deve primar para que as crenças e valores da população sejam respeitados e considerados como fontes de aprendizado mútuo na vivência e integração do conhecimento profissional e popular, rompendo o modelo tradicional de repasse do saber de forma vertical, "a um usuário passivo que deve modificar seu comportamento de acordo com o que lhe é recomendado" 8:24.

Por outro lado, existe um outro elemento, muito presente no trabalho das enfermeiras e que também representa fator fundamental para a vida do agricultor, que é a prática do uso de agrotóxicos nas lavouras. Este é um fenômeno que passou a integrar a vida do agricultor brasileiro nos anos cinqüenta e que foi absorvido como essencial para o aumento da produção e a possibilidade de sobrevivência no meio agrícola. Trata-se, neste caso, de uma cultura imposta pelo sistema no qual está inserido o produtor rural. A produção agrícola é proporcional ao uso dos "fertilizantes" e "defensivos agrícolas", passando a representar a única possibilidade de sobrevivência neste mercado, como a fala trazida por uma enfermeira: para nós, muitas vezes, é difícil uma mudança, imagina para o próprio agricultor que, se não usar agrotóxico, parece que não vai produzir. Então, tudo isso é o quanto a gente tem que trabalhar para chegar lá (e9). O uso indevido e indiscriminado destas substâncias químicas têm causado muitos problemas de saúde.

Outra característica encontrada no trabalho das enfermeiras, nestes municípios, relaciona-se com a divisão das atividades na equipe de enfermagem. Quando a enfermeira assume o papel de secretária de saúde esta divisão torna-se nítida, pois o trabalho da enfermeira prende-se mais ao de gestor em saúde, no município. Outra situação em que o trabalho da enfermeira fica evidente são nas ações relacionadas com a educação em saúde, trabalhos em grupos, coleta de material para o preventivo de câncer ginecológico, gerenciamento da unidade ou coordenação do Pro- grama de Agentes Comunitários de Saúde (PACS). Quando o trabalho refere-se aos procedimentos, não há uma separação nítida entre as ações que realizam as enfermeiras e as auxiliares de enfermagem. Isto pode ser verificado em situações como a triagem de clientes, na pré-consulta, a aplicação de vacinas, a realização de curativos, entre outras. Nestas situações, podese ver a enfermeira alternando papéis com a auxiliar de enfermagem, especialmente quando trabalham em duplas. Nestes casos, a auxiliar realiza o procedimento e a enfermeira faz as anotações e orientações ou o contrário. Percebe-se que não há preocupação em demarcar o trabalho da enfermeira, pois o seu papel parece estar evidente para as pessoas que são cuidadas e para os demais profissionais. Olha, claro que aqui a gente faz de tudo, as gurias daqui (auxiliares) e nós, as enfermeiras, fazemos de tudo um pouco [...] É claro que tem coisas que são só nossas, das enfermeiras, e tem coisas que são das auxiliares, como o preventivo que é a enfermeira que faz. [...] Do trabatho, en gosto de tudo, não tem o que en gosto mais de fazer (e2).

Outra enfermeira, que é a chefe do serviço de enfermagem da prefeitura, ao explicar como acontece a divisão de trabalho na enfermagem, diz que as tarefas são organizadas e distribuídas com o objetivo de que não aconteça sobrecarga de nenhum dos funcionários. Esta distribuição do trabalho se dá em reunião, na qual fica acertado o papel de cada um, como na fala: [...] a gente senta e diæ: gurias, vamos conversar, uma fica responsável pela sala de vacina, a gente meio que subdivide os serviços, para não sobrecarregar ninguém. Outra fica com a sala de curativos, no sentido de repor material, esterilização, aquela da vacina, se falta, ela fica encarregada de pedir na $4^{a}$ Coordenadoria Regional de Saúde, ver a temperatura, de mandar no final do mês. É tudo assim, cada uma com uma função. Então já fica mais fácil trabalhar [...] Senão acontece assim, tudo uma que faz, porque é tudo en, ninguém me ajuda [...] (e2).

Como pode ser percebido, por esta fala, existe uma distribuição de trabalho mais participativa, na qual a equipe se reúne e organiza uma escala com a função de cada funcionária, a fim de que não haja sobrecarga de trabalho para nenhum deles, permitindo, ainda, uma comunicação mais efetiva.

As atividades da enfermeira são integradas com as de outros setores que atuam no município, constituindo a organização social do município, são "os aliados na saúde", que planejam e executam atividades relacionadas com a saúde, tanto na cidade como na zona rural. Dentre eles destacam-se a Associação Riograndense de Empreendimentos de Assistência Técnica e Extensão Rural (EMATER), a Pastoral da Saúde, os Centros Comunitários, em cada uma das 
comunidades rurais, Clubes Recreativos e Esportivos, Grupos de Terceira Idade, Clubes de Mães, Secretarias Municipais de Agricultura e Educação, Companhia Riograndense de Saneamento (CORSAN), Movimento das Mulheres, como é o caso referido a seguir, por uma das enfermeiras: nós estamos fazendo um trabalho também com a questão da água, nós temos a água do interior com alto indice de contaminação, então a gente fa zum trabalho junto com a EMATER, que faz a parte de orientação, a prefeitura põe os recursos, estamos recuperando várias fontes. [...] Não seria só o nosso trabalho, mas temos vários aliados junto ao nosso trabalho, como a Pastoral da Saúde, que faz um bom trabalho(e6).

Um momento especial de entrosamento entre os diferentes setores é a Feira de Saúde do Município, realizada uma vez por ano, geralmente na semana do município, por ocasião do aniversário de emancipação, como ilustra a fala seguinte de uma enfermeira, Secretária de Saúde: a gente procura integrar, como nós temos poucos profissionais, uma vez.por ano a gente faz uma feira da saúde. Então, eu convido todas as entidades relacionadas com a saúde, a Liga Feminina, EMATER, CORS AN [...] tudo o que tiver no município. A gente faz, na praşa, dependendo do tempo a gente faz. no salão. Ai, sim, aquele dia eu paro, fecho o posto e todos os profissionais estão lá, cada um com suas ativida$\operatorname{des}[\ldots](\mathrm{e} 9)$.

Outra situação que ilustra esta integração efetiva entre os diferentes setores comunitários é o caso da constituição da "comissão municipal de cólera", em função de um alerta epidemiológico, ocorrido no período da coleta dos dados. É formada por um representante de cada um dos seguintes órgãos: Secretaria de Saúde, Secretaria de Educação, EMATER, CORSAN, cuja função é planejar e implementar medidas para intensificação da vigilância da doença e medidas de prevenção. Através de telefonemas, pela parte da manhã, a enfermeira, que desempenhava o papel de Secretária de Saúde, conseguiu reunir os diferentes representantes, na parte da tarde. A comunicação é mais rápida e a disponibilidade parece ser maior, até pela pequena distância entre os locais de trabalho e a necessidade de integração, pois cada órgão abrange um aspecto do problema, como é o caso da questão das doenças transmissíveis, dos problemas relacionados com a poluição ambiental, entre outros.

\section{O preparo da enfermeira: estratégias para cuidar}

A percepção e expectativas das enfermeiras em relação ao seu trabalho tem relação com o período em que se graduaram pois a formação deu-se entre os anos oitenta e noventa, sendo que somente uma delas formou-se em mil novecentos e setenta e dois. Para algumas delas, trabalhar em hospital era a única possibilidade frente à política de saúde, na época da conclusão da graduação, confirmando que "de maneira geral, a formação dos profissionais de saúde, historicamente se desenvolveu numa relação muito estreita com as políticas de saúde e econômica implementadas pelo estado" [...] ${ }^{9: 35}$. Das nove entrevistadas, três disseram ser o hospital a expectativa de trabalho, por ter tido pouco ou nenhum contato com a área de saúde pública, durante o desenvolvimento do curso. Todavia, mesmo iniciando neste local, com a municipalização da saúde, ocorrida no final da década de oitenta e nos anos noventa, houve a possibilidade de inserção na saúde pública.

A expectativa que predominou dentre as respostas das enfermeiras compreende a "possibilidade de trabalhar com a prevenção", em unidade de saúde, envolvendo mais "educação em saúde", "trabalhando com grupos", "resolvendo os problemas do mundo", pois "saúde pública é mais gratificante", "orienta as pessoas". Embora a possibilidade de orientar as pessoas e trabalhar com a prevenção sejam situações possíveis de serem realizadas também em outros ambientes, fica evidente a orientação transmitida no período da formação acadêmica das enfermeiras, na qual prevalece o discurso da separação da prevenção e tratamento como dois momentos independentes do processo saúde/doença.

Algumas saíram da graduação "cheias de sonhos e idéias", sendo uma profissional que "sempre buscaria crescer, aprender, melhorar", com muita "vontade de trabalhar e mudar as coisas", "tendo tudo para construir". Pensavam em "reunir a comunidade e ver o que queriam", "montar programas disso e daquilo", pois sentiam "necessidade de mudar a realidade", a partir dos problemas encontrados. Haveria, com isso, a possibilidade de "chegar na frente, pensar antes", "trabalhar a pessoa antes de adoecer, orientando, educando e conscientizando". Mais do que tudo isso, havia a expectativa de "trabalhar direito", "sabendo fazer o que foi aprendido". A possibilidade de transformar a realidade através de seu trabalho, com uma visão ingênua de que as pessoas não se cuidam porque não sabem, e que a enfermeira, sozinha, pode resolver os problemas de saúde da população, era uma visão comum na época da formação destas profissionais. Será que hoje ainda é este o discurso que é transmitido na formação das enfermeiras? Por outro lado, sente- 
se nestas expectativas, a presença de valores fundamentais da enfermagem e que estão presentes em discursos de estudantes e enfermeiras, como os relatados em pesquisa na qual a autora refere que: "as enfermeiras em seus discursos, discorreram sobre o sentido que atribuem ao exercício profissional. Em suas falas, fica evidenciada a enorme importância que a profissão assume em suas vidas. O sentido da profissão, que surge repleto de valor ético, de solidariedade, de ajuda ao ser humano, é enfocado, muitas vezes, associado ao nível de exigência para o seu exercício" ${ }^{\text {10:77. }}$.

Em relação à percepção do seu trabalho desempenhado no município, há um elemento comum a todas as enfermeiras: a manifestação do quanto se tornou gratificante o seu papel, pelo crescimento do mesmo com as inovações possibilitadas com a implantação do SUS e as políticas decorrentes. Hoje, questionam-se sobre o trabalho burocratizado em UBS, sendo que a maior realização fica por conta da relação da enfermeira com as pessoas, na qual há a possibilidade de uma maior interação pessoa a pessoa. Isto mostra a necessidade que a enfermeira sentiu, com a prática, de que o cuidado voltado às necessidades e desejos dos indivíduos ou comunidade, exige interação e conhecimento do sujeito cuidado. Isto fazia parte de um discurso da academia, mas que na verdade não era vivenciado desta maneira.

Para melhor desempenhar o seu papel elas utilizaram diferentes estratégias. Algumas iniciaram conhecendo a realidade, participando dos treinamentos da $4^{a}$ Coordenadoria Regional de Saúde, aplicando os programas propostos e, depois, passando a criar outros programas, de acordo com a realidade, além de manter os já existentes. Este grupo, que representa a maioria das enfermeiras pesquisadas, percebe o trabalho desenvolvido como sendo reconhecido, tanto por parte da população, como pela equipe de saúde: então, no início, en ficava mais na unidade de saúde, fazendo o trabalho de vacinas, triagem, verificação de pressão, curativos, ambulatório, esse tipo de coisa. Depois é que a gente começou a sentar e se organizar. Além dos programas que a $4^{a}$ Coordenadoria Regional de Saúde preconizava, a gente começou a ver a realidade da comunidade e montar programas em cima disso [...] Então, eu acho assim, agora tem sido muito gratificante superar as expectativas no sentido de poder realizar e ver os efeitos, quero realizar bem mais e a população acho que está ficando mais consciente, porque o agente de saúde indo de casa em casa, sempre falando e orientando [...](e2).

As estratégias utilizadas pelas enfermeiras para iniciar seu trabalho nas comunidades podem ser diferentes, mas demonstram a necessidade de buscar ca- minhos para a realização mais adequada do mesmo. Em geral, as profissionais vivem em conflito, porque elas até podem saber como é o melhor, mas estão pressionadas, porque têm que mostrar serviço, pois existe o trabalho a ser realizado, representado pela rotina da UBS e pelo qual são cobradas. De outro lado, nem sempre a expectativa da enfermeira em relação ao seu trabalho vai ao encontro daquela esperada pelos outros profissionais e pela população.

\section{CONSIDERAÇÕES FINAIS}

O modelo biologicista hegemônico que tem conduzido a formação dos profissionais da saúde, no caso deste estudo as enfermeiras, apresenta características marcadas por currículos organizados em disciplinas que enfatizam o conhecimento das doenças e o tratamento dos doentes. Como conseqüência, o lócus privilegiado para o "treinamento dos aprendizes" é o hospital; o conceito de saúde dominante é representado pela ausência de doenças; e o domínio da alta complexidade tecnológica é a principal meta dos cursos e das instituições de saúde. Este modelo e os espaços onde se desenvolve exercem uma profunda atração, tanto sobre os ingressantes nas carreiras da saúde, quanto na maioria dos profissionais. Representa o grande desafio do conhecimento na área e a crença de que, quem domina este nível de complexidade torna-se capaz de atuar nos demais níveis "inferiores". No limite é a conquista do poder sobre a vida e a morte. Mas, o movimento de transformação deste modelo vem se fortalecendo nas ultimas décadas, alavancado por políticas públicas aderidas às necessidades da população, como a Reforma Sanitária, implementada como SUS, bem como sua estratégia mais inovadora, o PSF.

$\mathrm{Na}$ mesma perspectiva, a concretização da Lei de Diretrizes e Bases de 1996 (LDB), através do estabelecimento das Diretrizes Curriculares, encaminha para a formação de profissionais mais preparados para as novas exigências da sociedade. A articulação entre as estratégias do Ministério da Saúde e os Projetos Pedagógicos dos cursos está em processo. Entre as possíveis sínteses que evidenciem a essência destas articulações, consideramos que o deslocamento da centralidade da formação para a promoção da saúde, a incorporação do conceito de saúde como qualidade de vida, o processo de trabalho pautado pela interdisciplinaridade, o desenvolvimento de competências, habilidades e atitudes para a ação social transformadora, fomentando a organização e a participação das pessoas, das famílias e das comunidades, bem como a capacitação para a educação em saúde, 
são aspectos fundamentais.

Todavia, muitos entraves precisam ser enfrentados: o temor pela perda de poder de algumas categorias; um entendimento equivocado de que as mudanças produzirão profissionais despreparados para a recuperação e reabilitação; o receio de esvaziamento dos currículos e dos cursos. Mas, a maior dificuldade, em nossa percepção, está no despreparo dos atuais educadores e trabalhadores da área da saúde para fomentarem e estimularem estas mudanças.

A era da incerteza que estamos vivendo, com acúmulo de exigências quanto à produtividade, acompanhada pelo enxugamento do número de trabalhadores nas várias áreas, gera insegurança permanente, pois cada novo dia não é sentido como tempo para a criação, mas sim como um conjunto de obstáculos a serem vencidos e inimigos a serem enfrentados, para garantir a sobrevivência. Neste contexto não é raro que discursos sobre as novas formas para enfrentamento desta realidade a ser superada, sejam recebidos com ironia e descrença. E aí se destaca a necessidade de produção de conhecimento que subsidie todos os atores envolvidos neste processo. Foi nesta perspectiva que este estudo foi proposto e desenvolvido.

Os dados coletados, transformados num conjunto e informações analisadas em profundidade, mostra vários vazios na formação das enfermeiras. Mas, mostra também o movimento de enfrentamento das profissionais, quando colocadas frente a uma realidade para a qual não se sentem adequadamente preparadas. Evidencia os caminhos trilhados e em processo de consolidação na medida em que estão respeitando as características culturais das comunidades rurais onde atuam.

Apesar de na aparência os modos de cuidar comunidades rurais possam não se diferenciar daqueles desenvolvidos em UBS urbanas, é em sua essência que os matizes da cultura e das relações de proximidade entre os sujeitos envolvidos vão delineando as especificidades. Estas especificidades culturais precisam ser consideradas em todos os grupos sociais, buscando alternativas de cuidados mais aproximadas entre o cuidado profissional e o popular, algumas vezes mantendo, outras negociando e outras remodelando o cuidado cultural ${ }^{11}$.

\section{REFERÊNCIAS}

1 Geertz C. A interpretação das culturas. Rio de Janeiro: Livros Técnicos e Científicos; 1989.

2 Budó MLD. A prática de cuidados em comunidades rurais e o preparo da enfermeira [tese]. Florianópolis (SC): Programa de Pós-Graduação em Enfermagem/UFSC; 2000.

3 Polit DF, Hungler B. Fundamentos de pesquisa em enfermagem. 3a ed. Porto Alegre: Artes Médicas; 1995.

4 Minayo MCS. O desafio do conhecimento: pesquisa qualitativa em saúde. São Paulo: Hucitec; 1992.

5 Conselho Nacional de Saúde (BR). Diretrizes e normas regulamentadoras da pesquisa envolvendo seres humanos: Resolução no 196/96. [citado 2003 Jul 22]. Disponível em: <http://www.ufrgs.br/hcpa/gppg/res19696.htm>.

6 Rossato R. Século XX: urbanização e cidadania. Santa Maria: Palloti; 1996.

7 Helman CG. Cultura, saúde e doença. 4a ed. Porto Alegre: Artmed; 2003.

8 Wendhausen A, Saupe R. Concepções de educação em saúde e a estratégia de saúde da família. Texto Contexto Enferm. 2003 Jan-Mar; 12: 17-25.

9 Bagnato MHS. Formação crítica dos profissionais da área de enfermagem. Texto Contexto Enferm. 1999 Jan-Abr; 8 (1): $31-42$.

10Cunha KC. O contexto e o processo motivacional vivenciado por enfermeiras [tese]. São Paulo (SP): Programa de PósGraduação da Escola de Enfermagem/USP; 1994.

11Leininger M. Culture care diversity and universality: a theory of nursing. New York: National League for Nursing Press; 1991. 